\title{
Squamous Cell Carcinomas on Bilateral Feet Arising in Long-Standing Eczematous Lesions
}

\author{
Aya Yamase, Yoko Funasaka, Takashi Ueno, Michiko Ito, \\ Yohei Otsuka, Seiji Kawana and Hidehisa Saeki \\ Department of Dermatology, Nippon Medical School, Tokyo, Japan
}

\begin{abstract}
We present a woman with squamous cell carcinomas on both feet in long-standing eczematous lesions. Histopathological examination of biopsies from the both feet revealed highly atypical cells invading the reticular layer of the dermis in the hyperkeratotic lesion and they were associated with surrounding dermatitis with spongiosis. Although the cause and etiology of eczema in our case is unclear, we speculate that the exceptionally long-lasting dermatitis might have induced double SCCs on bilateral feet with an unusual constitution. To the best of our knowledge, this is a first case of SCC on bilateral feet arising in long-standing eczematous lesions. (J Nippon Med Sch 2017; 84: 105-107)
\end{abstract}

Key words: squamous cell carcinoma, bilateral feet, eczema

A 64-year-old Japanese woman first visited our hospital in 2008 with a 39-year history of eczematous lesions on both feet. The eczema on her left foot had become gradually hyperkeratotic with fissures, which caused pain. However, there were no varicose veins or venous insufficiency in the legs, and the lesions had been treated with topical steroids for almost the entire duration of the disease. Clinical examination of the left foot showed a red hyperkeratotic plaque with ulceration, measuring approximately $5 \times 5 \mathrm{~cm}$ (Fig. 1a). A skin biopsy revealed invasion of atypical squamous cells into the dermis, and a squamous cell carcinoma (SCC) was confirmed (Fig. 1b), although she had never been exposed to carcinogenic substances, including arsenic or radiation therapy. Computed tomography (CT) of the head, chest, and abdomen, and a gallium scan revealed no organ metastases. The tumor was resected with a $1-\mathrm{cm}$ margin, and the wound was covered with a full-thickness skin graft. Histopathological examination of the resected specimen showed SCC with ulceration in the keratinized area, and 80 percent of the plaque had dermatitis with spongiosis surrounding the SCC or SCC in situ (Fig. 1c, d). After the resection, the patient presented for follow-up examinations every three months. The pruritic dermatitis on her right foot had been treated with topical steroids since the initial consultation. The dermatitis persisted for three years following the operation on the left foot. The lesion had periods of remission and exacerbation, but became progressively keratinized with partial erosions (Fig. 2a). Histopathological examination of a biopsy specimen from the right foot revealed highly atypical cells invading the reticular layer of the dermis in the hyperkeratotic lesion (Fig. 2b), and this was associated with surrounding dermatitis with spongiosis (Fig. 2c, d), suggesting that the hyperkeratotic erythematous lesion on the right foot was a SCC occurring in an area of long-standing dermatitis. Consideration of the lymphatic and hematogenous systems suggested that the tumors in the present case were double non-metastatic SCCs. The SCC on the right foot was resected with a $5-\mathrm{mm}$ margin, and the wound was covered with a full-thickness skin graft.

A relationship between inflammation and cancer has been suspected since Virchow noted leukocytes in neoplastic tissues ${ }^{1}$. In addition, inflammation has been shown to induce DNA damage via oxidative stress ${ }^{2}$, and cases of SCC associated with lichen simplex chronicus have been reported ${ }^{3-5}$. However, to the best of our knowledge, there have been no reports of SCC on the bilateral feet arising in long-standing eczematous lesions. Leverkus et al. reported a case of cutaneous SCC in a pa-

Correspondence to Aya Yamase, MD, Department of Dermatology, Nippon Medical School, 1-1-5 Sendagi, Bunkyo-ku, Tokyo 113-8603, Japan

E-mail: ayafoxy@nms.ac.jp

Journal Website (http://www2.nms.ac.jp/jnms/) 

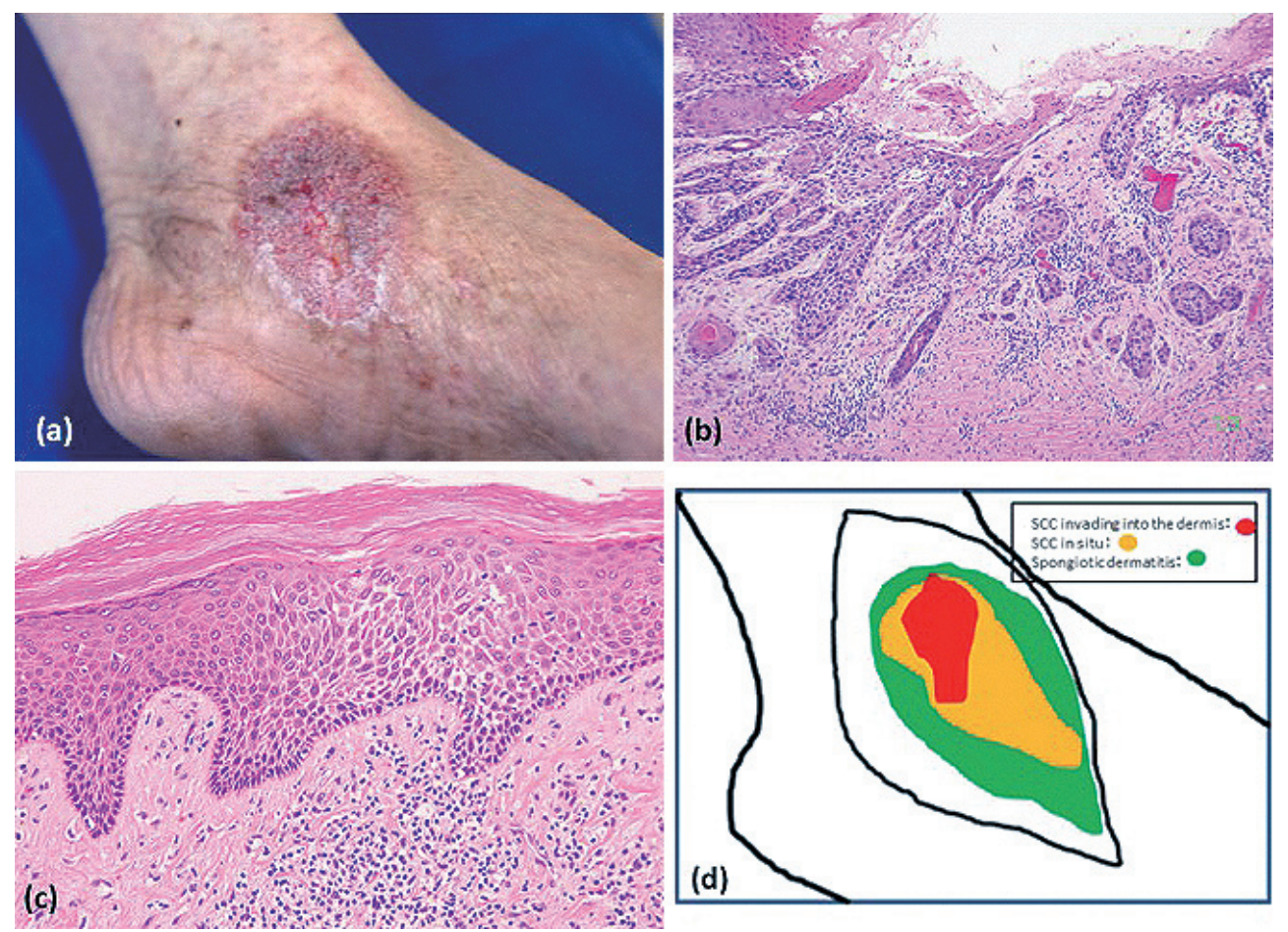

Fig. 1 (a) A reddish and hyperkeratotic plaque with ulceration, measuring approximately $5 \times 5$ $\mathrm{cm}$ at the medial border of the left foot. (b) Tumor nests consisted of atypical squamous cells that invaded the reticular layer of the dermis (H\&E stain; $\times 100$ ). (c) Inflammatory cells infiltrate the dermis, causing spongiosis in the epidermis (H\&E stain; $\times 100)$. (d) Illustration showing the location of the SCC and eczematous lesions on the left foot. The areas of SCC (red), SCC in situ (yellow) and spongiotic dermatitis (green) are highlighted.
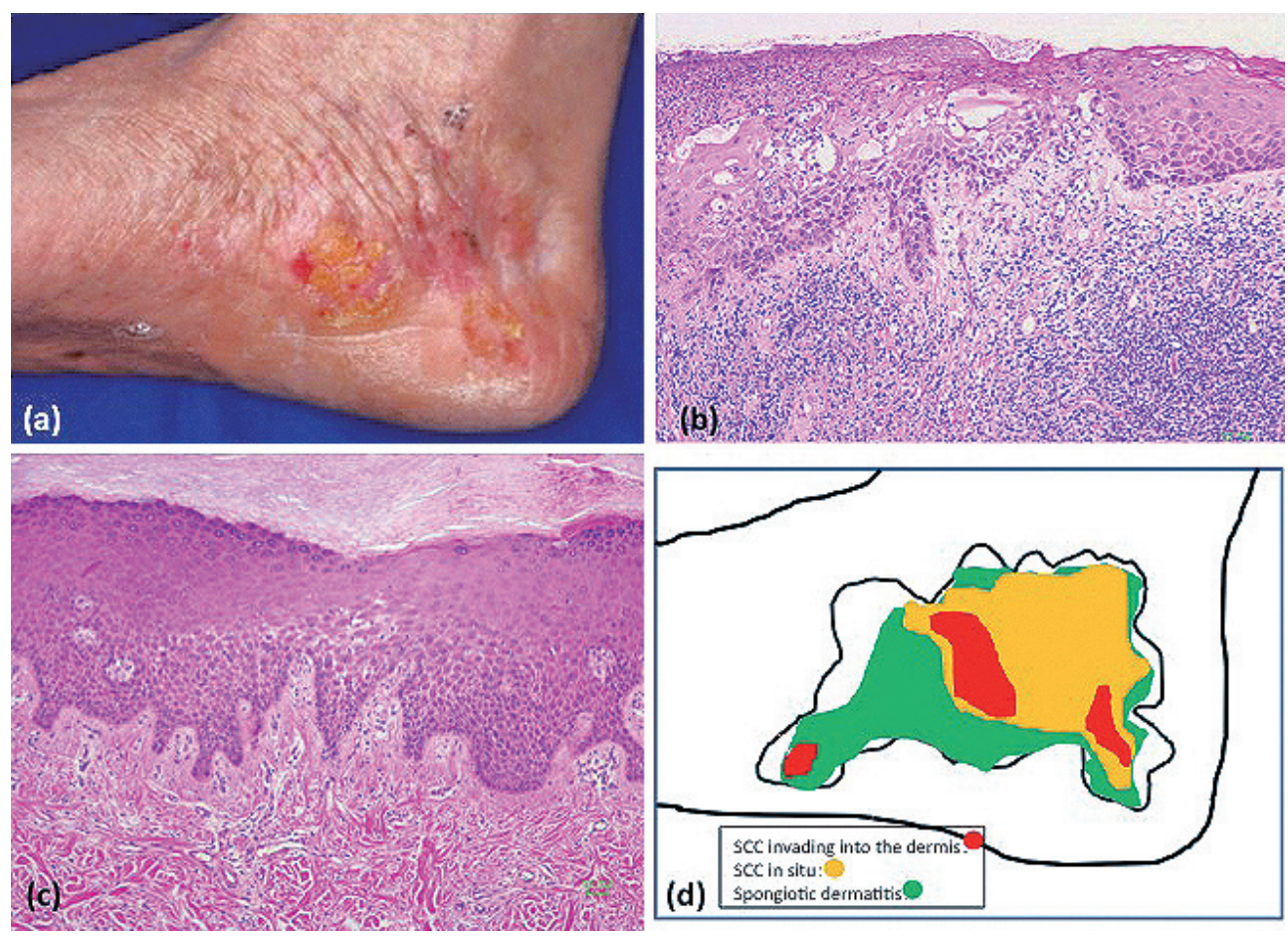

Fig. 2 (a) A scaly erythema with erosion on the right foot. (b) Atypical squamous cells in the stratum basale have invaded the reticular layer of the dermis (H\&E stain; $\times 100)$. (c) Inflammatory cells infiltrate the upper dermis, causing spongiosis in the epidermis (H\&E stain; $\times 100$ ). (d) Illustration showing the location of the SCC and eczematous lesions on the right foot. The areas of SCC (red), SCC in situ (yellow) and spongiotic dermatitis (green) are highlighted. 
tient with long-standing, untreated acrodermatitis chronica atrophicans ${ }^{6}$. Demehri et al. reported a case of chronic allergic contact dermatitis arising on an internal metal rod in the ankle and causing $\mathrm{SCC}^{7}$. They theorized that the patient's inflammation was not the result of cancer but was rather the driver of the carcinogenesis, because inflammation was also seen in the cancer-free margin of the excision. In our patient, inflammation was also seen in the cancer-free margin (Fig. 1d, 2d). Furthermore, the scratching of fissures associated with long-standing eczema is known to be a cause of skin cancer, such as Marjolin's ulcers ${ }^{8}$. Although the cause and etiology of our patient's eczema were unclear, we speculate that the exceptionally long-lasting dermatitis might have induced the SCCs on both feet.

\section{Conflict of Interest: None.}

\section{References}

1. Balkwill F, Mantovani A: Inflammation and cancer: back to Virchow? Lancet 2001; 357: 539-545.

2. Nishigori C, Hattori Y, Toyokuni S: Role of reactive oxy- gen species in skin carcinogenesis. Antioxid Redox Signal 2004; 6: 561-570.

3. Deshmukh P, Sharma YK, Chaudhari ND, Dogra BB, Deo KS: Multiple squamous cell carcinoma over lichen simplex chronicus: a rare entity. Indian J Dermatol 2013; 58: 329.

4. Tiengo C, Deluca J, Belloni-Fortina A, Salmaso R, Galifi F, Alaibac M: Occurrence of squamous cell carcinoma in an area of lichen simplex chronicus: case report and pathogenetic hypothesis. J Cutan Med Surg 2012; 16: 350-352.

5. Wu M, Wang Y, Bu W, Jia G, Fang F, Zhao L: Squamous cell carcinoma arising in lichen simplex chronicus. Eur J Dermatol 2010; 20: 858-859.

6. Leverkus M, Finner AM, Pokrywka A, Franke I, Gollnick $\mathrm{H}$ : Metastatic squamous cell carcinoma of the ankle in long-standing untreated acrodermatitis chronica atrophicans. Dermatology 2008; 217: 215-218.

7. Demehri S, Cunningham TJ, Hurst EA, Schaffer A, Sheinbein DM, Yokoyama WM: Chronic allergic contact dermatitis promotes skin cancer. J Clin Invest 2014; 124: 50375041.

8. Pekarek B, Buck S, Osher L: A comprehensive review on Marjolin's ulcers: diagnosis and treatment. J Am Col Certif Wound Spec 2011; 3: 60-64.

(Received, June 15, 2015)

(Accepted, March 23, 2016) 